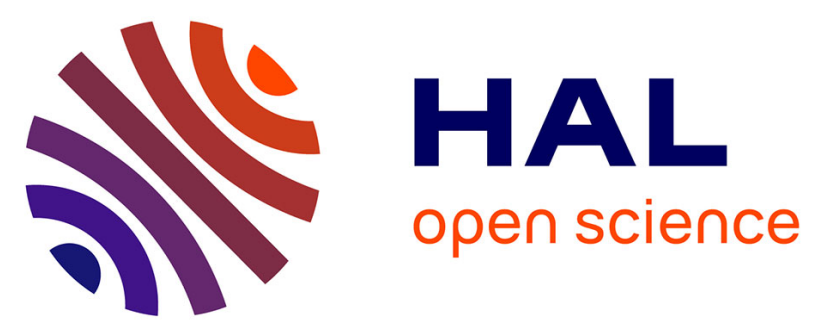

\title{
Pedigree-free quantitative genetic approach provides evidence for heritability of movement tactics in wild roe deer
}

Laura Gervais, A.J. Mark Hewison, Nicolas Morellet, Maria Bernard, Joel

Merlet, Bruno Cargnelutti, Yannick Chaval, Benoît Pujol, Erwan Quéméré

\section{To cite this version:}

Laura Gervais, A.J. Mark Hewison, Nicolas Morellet, Maria Bernard, Joel Merlet, et al.. Pedigree-free quantitative genetic approach provides evidence for heritability of movement tactics in wild roe deer. Journal of Evolutionary Biology, 2020, 10.1111/jeb.13594 . hal-02622271

\section{HAL Id: hal-02622271 \\ https://hal.inrae.fr/hal-02622271}

Submitted on 26 May 2020

HAL is a multi-disciplinary open access archive for the deposit and dissemination of scientific research documents, whether they are published or not. The documents may come from teaching and research institutions in France or abroad, or from public or private research centers.
L'archive ouverte pluridisciplinaire HAL, est destinée au dépôt et à la diffusion de documents scientifiques de niveau recherche, publiés ou non, émanant des établissements d'enseignement et de recherche français ou étrangers, des laboratoires publics ou privés. 
Pedigree-free quantitative genetic approach provides evidence for heritability of movement tactics in wild roe deer

Gervais L. ${ }^{1,2,3}$, Hewison A.J.M. ${ }^{1,2}$ Morellet N. ${ }^{1,2}$, Bernard M. ${ }^{4,5}$, Merlet J. ${ }^{1,2}$, Cargnelutti B. ${ }^{1,2}$, Chaval Y. ${ }^{1,2}$, Pujol B. ${ }^{3,6 *}$, Quéméré $E .1,2,7 *$

1Université de Toulouse, INRAE, CEFS, 31320, Castanet-Tolosan, France

2LTSER ZA PYRénées GARonne, 31320, Auzeville-Tolosane, France

${ }^{3}$ Laboratoire Évolution \& Diversité Biologique (EDB UMR 5174), Université Fédérale de Toulouse MidiPyrénées, CNRS, IRD, UPS, 31062 Toulouse, France

${ }^{4}$ Université Paris-Saclay, INRAE, AgroParisTech, GABI, 78350, Jouy-en-Josas,France

5INRAE, SIGENAE, 78350, Jouy-en-Josas, France

${ }^{6}$ PSL Université Paris : EPHE-UPVD-CNRS, USR 3278 CRIOBE, Université de Perpignan, 52 Avenue Paul

Alduy, 66860 Perpignan Cedex, France

${ }^{7}$ ESE, Ecology and Ecosystems Health, Agrocampus Ouest, INRAE, 35042, Rennes, France

*These authors contributed equally to this work as co-senior author.

Short title: Heritability of spatial behaviour in the wild

Corresponding authors: Laura Gervais, lauragervais51@gmail.com and Erwan Quéméré, erwan.quemere@inra.fr. Phone: (+33) 561285497

This article has been accepted for publication and undergone full peer review but has not been through the copyediting, typesetting, pagination and proofreading process, which may lead to differences between this version and the Version of Record. Please cite this article as doi: $\underline{10.1111 / J E B .13594}$

This article is protected by copyright. All rights reserved

Gervais, L. (Auteur de correspondance), Hewison, A. M., Morellet, N., Bernard, M., Merlet, J. 
MISS LAURA GERVAIS (Orcid ID : 0000-0002-7636-4818)

DR ERWAN QUEMERE (Orcid ID : 0000-0002-3880-1933)

Article type : Research Papers

\section{Pedigree-free quantitative genetic approach provides evidence for heritability of movement tactics in wild roe deer}

Short title: Heritability of spatial behaviour in the wild

\section{Abstract: 215 words}

Assessing the evolutionary potential of animal populations in the wild is crucial to understanding how they may respond to selection mediated by rapid environmental change (e.g. habitat loss and fragmentation). A growing number of studies have investigated the adaptive role of behaviour, but assessments of its genetic basis in a natural setting remain scarce. We combined intensive biologging technology with genome-wide data and a pedigree-free quantitative genetic approach to quantify repeatability, heritability and evolvability for a suite of behaviours related to the risk avoidanceresource acquisition trade-off in a wild roe deer (Capreolus capreolus) population inhabiting a heterogeneous, human-dominated landscape. These traits, linked to the stress response, movement and space-use behaviour, were all moderately to highly repeatable. Furthermore, the repeatable among-individual component of variation in these traits was partly due to additive genetic variance, with heritability estimates ranging from $0.21 \pm 0.08$ to $0.70 \pm 0.11$ and evolvability ranging from 1.1 to 4.3\%. Changes in the trait mean can therefore occur under hypothetical directional selection over just a few generations. To the best of our knowledge, this is the first empirical demonstration of additive genetic variation in space-use behaviour in a free-ranging population based on genomic relatedness data. We conclude that wild animal populations may have the potential to adjust their spatial behaviour to human-driven environmental modifications through micro-evolutionary change.

Keywords (3-6 keys word): evolutionary potential, repeatability, personality variation, animal model, evolvability, genomic relatedness matrix

This article is protected by copyright. All rights reserved 


\section{Introduction}

Over evolutionary time, all organisms have evolved in relation to the environmental heterogeneity that is a ubiquitous feature in the wild. However, because recent human-induced environmental change is increasingly rapid, organisms are currently experiencing novel and rapidly fluctuating conditions to which they must adjust over very short timescales (Parmesan, 2006). This adjustment occurs mainly through two non-exclusive mechanisms, by modification of the phenotype (i.e. microevolutionary change, phenotypic plasticity) or by modification of the environment (i.e. selection or adjustment of the environment) (Edelaar \& Bolnick, 2019). Behaviour plays an essential role in this adjustment since it is a key mediator of the relationship between an organism and its environment. Indeed, it is generally considered to be one of the most plastic components of the phenotype (Tuomainen \& Candolin, 2011). However, behavioural plasticity may not suffice to sustain a directional response, and micro-evolutionary change may be required for a population to adapt to a highly modified environment (Both \& Visser, 2001; Wong \& Candolin, 2015).

A genetic basis for behavioural variation among individuals is the raw material for adaptive evolution, assuming that the ability of certain behavioural phenotypes to cope with novel conditions provides them with a fitness benefit. Long considered as statistical noise (Wilson, 1998), behavioural variation among individuals is currently a central focus for behavioural ecologists. Many recent studies have highlighted the remarkable consistency of behavioural differences among individuals across time and ecological contexts in a wide range of taxa (also known as "personality traits" Réale, Reader, Sol, McDougall, \& Dingemanse, 2007). While this consistency (aka repeatability) does not preclude a degree of behavioural plasticity, it implies that an individual does not express the entire range of behavioural responses observed within the population. To predict how animals will behaviourally adjust to a novel environmental context, we need to evaluate the respective importance of personality and plasticity in observed behavioural variation and to quantify the extent to which personality variation is heritable. Adaptive explanations for the existence of consistent among-individual differences assume that phenotypic variation reliably reflects additive genetic variation (i.e. "the phenotypic gambit" Grafen, 1984). Studies under controlled conditions have reported heritability values encompassing the widest range possible (from 0 to $100 \%$ ), with a $30 \%$ average (Mousseau \& Roff, 1987; Stirling, Réale, \& Roff, 2002; Van Oers \& Sinn, 2013). Postma (2014) recently estimated an average heritability of $50 \%$ across wild populations. However, this value is probably inflated because additive genetic effects may be confounded with non-genetic permanent environmental effects in field studies (Dingemanse \& Dochtermann, 2014). As a consequence, whether the phenotypic gambit generally holds for personality variations in the wild

This article is protected by copyright. All rights reserved 
remains unclear. Hence, it is crucial to evaluate the genetic and environmental basis of amongindividual variation in behaviour which can only be reliably assessed when both heritability and repeatability are estimated simultaneously (Dochtermann, Schwab, \& Sih, 2014).

Measuring behavioural repeatability in free ranging populations is challenging. As a consequence, most studies of wild animals index personality variation using common garden experiments (Archard \& Braithwaite, 2010), likely constraining an individual's behavioural repertoire. Individual specialisation in spatial behaviour underlies many personality traits, for example, activity or exploratory behaviour, both of which are linked to movement and space-use. Recent advances in biologging technology offer the opportunity to study the interaction between individual spatial behaviours and the environmental context in which these behaviours are expressed. However, the use of tracking technologies to assess facets of personality linked to movement has only recently been exploited (Nilson et al., 2014; Spiegel et al., 2017; Spiegel et al., 2015; Villegas-Ríos et al., 2017; Ward-Fear et al., 2018). Furthermore, while it is well established that some exceptional movements such as natal dispersal or migration are partly genetically based (Charmantier, Buoro, Gimenez, \& Weimerskirch, 2011; Greenwood, Harvey, \& Perrins, 1979; Saastamoinen et al., 2018; Waser \& Jones, 1989), little is known about the genetic variation underpinning routine movement behaviours that drive most space-use behaviour. In order to evaluate their evolutionary potential, it is therefore necessary to use an integrative approach, combining the movement ecology and personality frameworks with quantitative genetics.

Measuring genetic variance and the heritability of a trait in wild populations requires estimates of pairwise relatedness amongst individuals (Lynch \& Walsh, 1998). Expected relatedness estimates have traditionally been calculated on the basis of population-level multigenerational pedigrees, which are themselves based on field observations or on parentage assignment inferred from multilocus genotypes (Wilson et al., 2010). Advances in high-throughput sequencing technologies mean that it is now possible to directly estimate realised pairwise genetic relatedness from genomic data (thousands of SNPs) in free-ranging organisms at a reasonable cost (Gervais et al., 2019; Gienapp et al., 2017). In this study, we combined a pedigree-free quantitative genetic approach with high spatio-temporal resolution monitoring of individual behaviour in a large sample of free ranging roe deer (Capreolus capreolus) inhabiting a highly heterogeneous agricultural landscape. This landscape has been extensively modified by human activities (e.g. agricultural practice, infrastructures) such that high quality foraging resources occur in locations where human disturbance is also high. Hence, animals must trade-off acquisition of high-quality resources against risk avoidance (Bonnot et al.,

This article is protected by copyright. All rights reserved 
2015). We quantified within- and among-individual variation in four behavioural traits and two physiological traits related to stress management, space-use and movement behaviour. We then implemented a genomic relatedness matrix to quantify trait genetic and non-genetic components of variation and assess their evolutionary potential.

\section{Materials \& methods}

\section{Study area and data collection}

This study is based on the long-term monitoring by capture-mark-recapture of a free-ranging

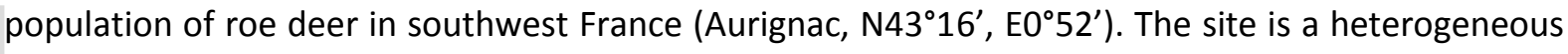
agricultural landscape of around 19,000 ha, with open fields, small woodland patches and two larger forest blocks. Human disturbance is high, with roads and buildings (i.e. villages, farms) widely distributed. Roe deer hunting occurs regularly from September to February with dogs, and by stalking of male adults only from June to September.

Three hundred and thirty four roe deer were caught between 2002 and 2018 during annual winter capture operations using drive netting. When a roe deer was caught in the net, it was tranquilized with an intra-muscular injection of acepromazine (Calmivet-3cc) and placed in a wooden retention box designed to minimize stress and risk of injury. During marking procedures (ca. 10 mins/animal), each animal was sexed, aged as adult ( $>1$ year old) or juvenile ( $<1$ year old) in relation to tooth eruption (Ratcliffe \& Mayle, 1992) and ear tagged. Blood and skin were sampled for subsequent analyses of the physiological stress response to capture and genetic information, respectively. The total time elapsed from capture in the net to release was recorded for each individual. Mean ambient temperature $\left({ }^{\circ} \mathrm{C}\right)$ for each capture event was provided by the nearest Meteo-France weather station. All capture and marking procedures were in accordance with French and European law for animal welfare (prefectural order from the Toulouse Administrative Authority to capture and monitor wild roe deer and agreement no. A31113001 approved by the Departmental Authority of Population Protection). For more details on the capture procedure and ethical considerations, see Morellet et al. (2009) and Bonnot et al. (2018).

\section{Physiological and behavioural responses to capture}

Capture can be considered as a form of acute stress for wild animals which should provoke a suite of physiological (e.g. hyperthermia, change in blood parameters) and behavioural (Moberg \& Mench, 2000; Moe \& Bakken, 1997) responses. Since 2009, we continuously measured rectal temperature to

This article is protected by copyright. All rights reserved 
the nearest $0.1^{\circ} \mathrm{C}$ during handling and recorded the average of the temperature at the beginning and at the end of the marking procedure as a measure of stress-induced hyperthermia. Individuals with abnormally low body temperature $\left(T^{\circ} \mathrm{C}<36.9\right)$ were removed from the dataset $(n=5)$. Haematological parameters were assessed on blood samples taken from the jugular vein $(10 \mathrm{~mL})$. Differential white cell counts were performed by visual determination on the first 100 WrightGiemsa-stained blood smears to quantify the proportion of lymphocytes and neutrophils in relation to the total white cell count. We calculated the ratio of neutrophils to lymphocytes (hereafter NL ratio) as an indicator of the chronic stress response (Davis, Maney, \& Maerz, 2008). In a recent work on three roe deer populations experiencing fluctuating environmental conditions, Carbillet et al. (2019) showed that this measure was consistently repeatable, irrespective of the capture protocol and provided an informative indicator of chronic stress that is partly related to environmental quality (e.g. food availability and quality, human disturbance). Finally, we recorded a behavioural score (hereafter docility) to index the individual's overall response to handling using a simple binary metric: we attributed a score of one if the individual struggled during manipulation (non-docile individuals), or a score of zero if the individual was passive (docile).

\section{Space-use and mobility}

Most of the studied deer (286 out of 334) were equipped with GPS collars to monitor individual space-use and movement. Collars were programmed to obtain a GPS fix every four hours (in 2003 and 2004) or every six hours (from 2005 to 2018) for approximately one year (baseline monitoring). In addition, the collars were programmed to obtain a GPS fix at high frequency (1 location/10 min) over a $24 \mathrm{~h}$ period approximately once per month (intensive monitoring). We performed differential correction to improve fix accuracy (Adrados, Verheyden-Tixier, Cargnelutti, Pépin, \& Janeau, 2003) and removed aberrant GPS fixes that would imply unfeasible movements ( $0.05 \%$ of all locations). We also removed all GPS fixes taken during the first 10 days after capture because of the potential alteration of spatial behaviour (Morellet et al., 2009). Furthermore, as one third of juveniles disperse (Debeffe et al., 2012), we only retained locations recorded after the dispersal period (from the end of March to the end of May, Debeffe et al., 2012) for deer classified as dispersers ( $n=45)$ to ensure that we analysed routine home range behaviour only. Finally, we also removed those months that had less than 15 days (for baseline monitoring) or less than 20 hours (for intensive monitoring) of data for a given individual.

Based on aerial photographs of the study site (from the IGN's BD Ortho, http://professionnels.ign.fr/bdortho-50cm), we manually digitized homogeneous habitat polygons

This article is protected by copyright. All rights reserved 
(in ArcView GIS 3.3, Esri, Redlands, CA, U.S.A.). Each polygon was then assigned to a habitat type (e.g. woodland, hedgerow, meadow or crop) that was determined annually by field observations during summer. Meadows and agricultural crops are numerous in the study system and provide abundant high quality resources (Abbas et al., 2011; Hewison et al., 2009), but are also more exposed to human disturbance and associated risks (e.g. road traffic accidents, agricultural practices, hunting) (Coulon et al., 2008; Martin et al., 2018; Padié et al., 2015). Roe deer are known to actively avoid roads and open habitats during daytime, when human disturbance is high (Bonnot et al., 2013; Martin et al., 2018; Padié et al., 2015).Thus, we assessed roe deer space-use behaviour in terms of risk taking as the probability of being in open habitat (i.e. meadows or crop fields) during daytime (hereafter $P_{O H}$, Bonnot et al., 2015), and the proximity to roads.

$P_{O H}$ was calculated as the average proportion of fixes at 12:00 that occurred in open habitat, ranging between 0 for an individual that was always located in closed habitat during daytime, and 1 for an individual always located in open habitat during daytime. For each individual and each GPS fix at 12:00, we also measured the distance $(\mathrm{km})$ to the nearest road (hereafter distance to roads). $P_{O H}$ and distance to roads were averaged per month in order to describe seasonal variation. Finally, we measured movement behaviour by calculating daily average speed $\left(\mathrm{km} \cdot \mathrm{h}^{-1}\right)$ during the intensive monitoring periods as the total distance travelled during $24 \mathrm{~h}$ (sum of step lengths) divided by the total interval duration (approx. 24h) (package adehabitatLT, Calenge, 2015), and averaged these values per month for each individual.

\section{Genomic relatedness}

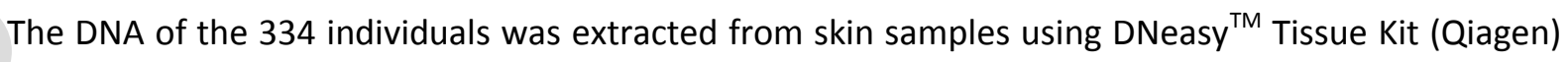
and genotyped using a double-digest RAD sequencing approach (Peterson, Weber, Kay, Fisher, \& Hoekstra, 2012) following the procedure detailed in Gervais et al. (2019). Briefly, individuals DNA was digested using two restriction enzymes, EcoR1 and MsPI, and size-selected libraries of 270-330 bp insert-size were sequenced on Illumina HiSeq 2500 (V4) (paired-end reads of 125 bp) so as to obtain an average depth of coverage of 76 reads/loci. De novo reconstruction of markers (i.e without a reference genome) and SNP calling was carried out with Stacks 1.35 software (Catchen, Hohenlohe, Bassham, Amores, \& Cresko, 2013). After removing loci present in less than $80 \%$ of individuals and with Minor-Allele-Frequency (MAF) lower than 1\%, we retained 14,887 polymorphic loci with a very low rate of genotyping error ( $<1 \%)$ and missing data (<6\%) (see Gervais et al., 2019 for more details). This final dataset was used to compute the Genomic Relatedness Matrix (GRM) of

This article is protected by copyright. All rights reserved 
the population using identity by state (IBS) SNP relationships as implemented in the GCTA software tool (Yang, Lee, Goddard, \& Visscher, 2011).

\section{Quantitative genetic analyses}

Our aim was to partition the phenotypic variance for fitness-related behavioural and physiological traits (Bonnot et al., 2018; Monestier et al., 2015) into among- and within-individual variation, and then partition among-individual variation into its genetic and non-genetic (permanent environmental effects) components. We used Linear-Mixed-effect Models (LMMs) where parameters were calculated using the REstricted Maximum Likelihood (REML) approach (Lynch \& Walsh, 1998). This approach, also called the "animal model" in quantitative genetics, partitions the phenotypic variance $\left(V_{P}\right)$ into additive genetic variance $\left(V_{A}\right)$, permanent environmental variance $\left(V_{P E}\right)$ and residual variance $\left(\mathrm{V}_{R}\right)$, so that $\mathrm{V}_{P=} \mathrm{V}_{\mathrm{A}}+\mathrm{V}_{\mathrm{PE}}+\mathrm{V}_{\mathrm{R}}$ conditional on any fixed effects. We included ageclass and sex as fixed effects in all models because behavioural traits may differ between life history stages and sexes (Debeffe et al., 2015). We also included a year effect to account for inter-annual differences in individual behaviour and environmental conditions in all models. In addition, in models investigating variation in response to the capture event (body temperature, NL ratio and docility), we included as fixed effects (i) the cumulative number of capture events for each individual, because repeated capture might lead to habituation and an attenuation of the behavioural response (Bonnot, Bergvall, Jarnemo, \& Kjellander, 2018) and (ii) the time between the actual capture event and release (i.e. time delay) to control for potential fluctuations in the stress response, assuming a linear relationship with time elapsed (Montané et al., 2007). In the few cases $(n=14)$ where the time delay was not available, we used the population average time delay (248 $\min$ ). For the body temperature model only, we additionally included the mean ambient temperature $\left({ }^{\circ} \mathrm{C}\right)$ during capture. In models investigating variation in space-use and movement behaviour $\left(P_{\mathrm{OH}}\right.$, distance to roads and daily average speed), we additionally included month (1-12) and sex and their two-way interaction as fixed effects to account for potential divergence in temporal variation between the sexes. Finally, as recommended by Wilson (2008), all models were also run with "methodological bias" fixed-effects only (thus, excluding all fixed-effects related to biological or temporal variation i.e. age-class, sex, year of capture and month of observation) (Table S2).

We decomposed phenotypic variance conditioned on fixed effects, into within- $\left(V_{R}\right)$ and amongindividual variance $\left(V_{\text {IND }}\right)$, including individual identity as a random effect on the intercept. $V_{R}$ represents within-individual variance due to plasticity and/or measurement error. The repeatability

This article is protected by copyright. All rights reserved 
of traits was estimated as ind ${ }^{2}=V_{\mathrm{IND}} /\left(V_{\mathrm{IND}}+V_{\mathrm{R}}\right)$ (Nakagawa \& Schielzeth, 2010). As suggested by Dochtermann \& Royauté (2019), we also reported a mean-squared standardised metric as $I_{I}=V_{I N D} / \bar{X}^{2}$, where $\bar{X}$ corresponds to the trait mean, to allow for direct comparison of the magnitude of the among-individual variation across traits (on a ratio or log scales, see below for further details). Second, we estimated additive genetic and non-genetic variation by decomposing among-individual variation into additive genetic variance $\left(V_{A}\right)$ and permanent environmental variance $\left(V_{P E}\right)$, including relatedness between pairs of individuals (GRM) as a random effect on the intercept so that $V_{I N D}=V_{A}+V_{P E}$ with $V_{P=} V_{I N D}+V_{R}$. Note that the GRM was non-positive definite but could nevertheless be implemented in an REML animal model (see Gilmour, 2010; Gilmour, 2019; Meyer, 2019 for implementation of none-positive definite matrix).

Narrow sense heritability of the traits was estimated as $h^{2}=V_{A} /\left(V_{A}+V_{\mathrm{PE}}+V_{R}\right)$ and the permanent environmental effect as $p e^{2}=V_{P E} /\left(V_{A}+V_{P E}+V_{R}\right)$, while the within-individual effect was approximated by the residual effect calculated as $r^{2}=V_{R} /\left(V_{A}+V_{P E}+V_{R}\right)$ (Wilson et al., 2010). Evolvability of the traits was estimated using the additive genetic variance standardized by the square mean of the trait as $I_{A}=V_{A} / \bar{X}^{2}$ where $\bar{X}$ is the trait mean before selection (Houle, 1992). This can be interpreted as the expected rate of trait change if it were submitted to a selection pressure which was as strong as on fitness itself ("a unit strength of selection", Houle, 1992). Evolvability is interpretable for traits on a log-interval or ratio measurement scale (Garcia-Gonzalez, Simmons, Tomkins, Kotiaho, \& Evans, 2012), but is not appropriate for traits without a natural zero point, proportions, or traits with a mean of zero (Hansen, Pélabon, \& Houle, 2011). As a consequence, we do not report evolvability estimates for body temperature, docility or $P_{\mathrm{OH}}$. For log-transformed data (NL ratio, distance to roads, daily average speed, see below), we directly used the additive genetic variance as an approximation of $I_{A}$ on a raw scale (Garcia-Gonzalez, Simmons, Tomkins, Kotiaho, \& Evans, 2012; Hansen et al., 2011).

All analyses were run on ASREML-R v4.00 (Butler, Cullis, Gilmour, \& Gogel, 2009). After inspecting the distributions of residuals for the models, we decided to log-transform traits with continuous distributions to meet assumptions of homoscedasticity and normality of residuals (with the exception of body temperature and $P_{O H}$ that already had normally distributed residuals and distance to roads that was $\log (x+1)$ transformed). We analysed the binary trait (docility) as if it was Gaussian, assuming that a discontinuous phenotype is determined by an underlying continuous distribution with a threshold above which the behaviour is considered to be expressed and below which it is not (Elston, Hill, \& Smith, 1977; Roff, Stirling, \& Fairbairn, 1997; Van Vleck, 1972). We report the heritability estimate for docility on the true data-scale (see Dempster \& Lerner, 1950). Note that

This article is protected by copyright. All rights reserved 
REML animal models with a binary data distribution family are known to underestimate all the variance components (Butler et al., 2009) and that estimates from threshold models must also be interpreted with caution (de Villemereuil, 2018; de Villemereuil, Schielzeth, Nakagawa, \& Morrissey, 2016). Finally, the statistical significance of variance components was assessed using Likelihood Ratio Tests (LRT) (Pinheiro \& Bates, 2006), assuming that twice the difference in log-likelihood between nested models follows a chi-squared distribution with one degree of freedom.

\section{Results}

\section{Data summary}

The number of times that each of the 334 individuals was captured ranged from one to six, with a mean of 1.93 captures per individual. Of the 286 individuals equipped with GPS collars, 10 individuals were removed due to an insufficient number of days monitoring. The mean number of monitoring days per individual was 330 (ranging from 57 to 1,268). See Table S1 for more details on sample size, means and phenotypic variance $\left(V_{P}\right)$ of traits. The Genomic Relatedness Matrix included 55,945 pairwise relatedness coefficients, of which 825 pairs had a relatedness coefficient higher than 0.1 . The majority of individuals were unrelated (see Figure S1). The total variance of the relatedness coefficient off-diagonal in the population was 0.014 .

This article is protected by copyright. All rights reserved 


\section{Partitioning trait variation into between- and within-individual components}

We found moderate to high levels of consistent among-individual variation (repeatability) for all the behavioural and physiological traits studied (Figure 1, Table 1). First, traits relating to stress management yielded similar levels of repeatability $\left(r^{2} \pm S E\right)$, ranging from $0.26 \pm 0.10$ for docility, to $0.31 \pm 0.12$ for the $N L$ ratio, and $0.38 \pm 0.11$ for body temperature (Figure 1). Second, movement behaviour (daily average speed) was similarly repeatable $\left(r^{2}=0.29 \pm 0.03\right)$. Finally, individuals showed a high level of consistency in space-use behaviour, with a repeatability of $0.62 \pm 0.02$ for $P_{O H}$ and $0.76 \pm 0.02$ for distance to roads (Figure 1). However, although highly repeatable, distance to roads had the lowest value for mean-squared standardised among-individual variation $\left(\mathrm{l}_{I}=1.2 \pm 0.1 \%\right)$. In contrast, the NL ratio was moderately repeatable, but had the highest level of among-individual variation $\left(\mathrm{l}_{1}=8.3 \pm 3.3 \%\right)$. Therefore, among individual variation was more marked for the $N L$ ratio than for distance to roads.

\section{Estimating additive genetic and permanent environmental variance}

We found statistically significant additive genetic variance for traits related to space-use and movement, but not for traits related to stress management (body temperature, NL ratio, docility) (Table 1). Narrow sense heritability $\left(h^{2} \pm \mathrm{SE}\right)$ differed markedly among traits (Figure 1$)$, ranging from $0.16 \pm 0.15$ for the $N L$ ratio to $0.70 \pm 0.11$ for distance to roads, while the permanent environmental effects $\left(\mathrm{pe}^{2}\right)$ ranged from $0.05 \pm 0.10$ for distance to roads to $0.20 \pm 0.09$ for $P_{O H}$. Evolvability $\left(\mathrm{I}_{\mathrm{A}} \pm \mathrm{SE} \%\right)$ also differed markedly among traits, ranging from $1.1 \pm 0.2 \%$ to $4.3 \pm 4.2 \%$ for distance to roads and $N L$ ratio, respectively. The level of among-individual variation in the three stress management behaviours was similarly moderate. However, the models were unable to tease apart the genetic and permanent environmental components for these three traits, despite non-zero additive genetic variance (for $N L$ ratio $h^{2}=0.16 \pm 0.15, \chi^{2}(1, N=301)=1.018, P=0.313$, for docility $h^{2}=0.17 \pm 0.12$, $\chi^{2}(1, N=334)=3.442, P=0.063$ and for body temperature $\left.h^{2}=0.32 \pm 0.16, \chi^{2}(1, N=329)=3.525, P=0.060\right)$. In contrast, we were able to estimate both additive genetic and permanent environmental variances for daily average speed, despite a moderate level of repeatability $\left(r^{2}=29 \%\right)$. Lastly, among-individual variation for traits related to movement and space-use behaviours (daily average speed, $P_{\mathrm{OH}}$ and distance to roads) was mostly attributed to additive genetic variance $\left(h^{2}=0.21 \pm 0.08,0.41 \pm 0.10\right.$ and $0.70 \pm 0.11$, respectively) (Figure 1 , Table 1 ).

This article is protected by copyright. All rights reserved 
Table 1. Variance component estimates and their associated ratios for stress management, space-use and movement behaviours. Components of phenotypic variance $\left(V_{P E}\right.$ : permanent environmental variance, $V_{A}$ : additive genetic variance, $V_{R}$ : residual variance) and their associated ratios (ind ${ }^{2}$ : repeatability, pe ${ }^{2}$ : permanent environmental effects, $h^{2}$ : heritability, $r^{2}$ : residual effect, $l_{1}$ : mean-squared standardised among-individual variation and $I_{A}$ : evolvability) are reported with their standard errors in brackets. $V_{I N D}$ : among-individual variance is the sum of $\mathrm{V}_{\mathrm{PE}}$ and $\mathrm{V}_{\mathrm{A}}$. Note that repeatability estimates and associated statistics were derived before the inclusion of the genetic effect. Significance of $i n d^{2}, h^{2}, p e^{2}$ was assessed with a LRT test (Chi-square statistic $\left(\chi^{2}\right)$ and $p$-value $(P)$ with one degree of freedom). $I_{A}$ values are only reported for variables on a log-interval or ratio scale.

\begin{tabular}{|c|c|c|c|c|c|c|c|c|c|}
\hline Variables & ind $^{2}$ & $V_{P E}$ & $V_{A}$ & $V_{R}$ & $p e^{2}$ & $h^{2}$ & $r^{2}$ & $\begin{array}{l}I_{A} \\
(\%)\end{array}$ & $\begin{array}{l}I_{I} \\
(\%)\end{array}$ \\
\hline Body & $0.38(0.11)$ & $0.033(0.060)$ & $0.117(0.062)$ & $0.218(0.034)$ & $0.09(0.16)$ & $0.32(0.16)$ & $0.59(0.10)$ & - & - \\
\hline \multirow[t]{2}{*}{ temperature } & $\chi^{2}=11.986$ & & & & $\chi^{2}=0.248$ & $\chi^{2}=3.525$ & & & \\
\hline & $P<0.001$ & & & & $P=0.618$ & $P=0.060$ & & & \\
\hline \multirow[t]{3}{*}{ NL ratio } & $0.31(0.12)$ & $0.043(0.046)$ & $0.043(0.042)$ & $0.184(0.030)$ & $0.16(0.17)$ & $0.16(0.15)$ & $0.68(0.12)$ & $4.3(4.2)$ & $8.3(3.3)$ \\
\hline & $\chi^{2}=6.116$ & & & & $\chi^{2}=0.936$ & $\chi^{2}=1.018$ & & & \\
\hline & $P=0.013$ & & & & $P=0.333$ & $P=0.312$ & & & \\
\hline \multirow[t]{3}{*}{ Docility } & $0.26(0.10)$ & $0.020(0.031)$ & $0.040(0.028)$ & $0.172(0.023)$ & $0.09(0.13)$ & $0.17(0.12)$ & $0.74(0.10)$ & - & - \\
\hline & $\chi^{2}=8.526$ & & & & $\chi^{2}=0.528$ & $\chi^{2}=3.442$ & & & \\
\hline & $P=0.003$ & & & & $P=0.467$ & $P=0.063$ & & & \\
\hline \multirow[t]{3}{*}{$P_{\mathrm{OH}}$} & $0.62(0.02)$ & $0.013(0.006)$ & $0.027(0.008)$ & $0.026(0.001)$ & $0.20(0.09)$ & $0.41(0.10)$ & $0.39(0.03)$ & - & - \\
\hline & $\chi^{2}=1396.455$ & & & & $\chi^{2}=5.728$ & $\chi^{2}=26.430$ & & & \\
\hline & $P<0.001$ & & & & $P=0.016$ & $P<0.001$ & & & \\
\hline \multirow[t]{3}{*}{ Distance to roads } & $0.76(0.02)$ & $<0.001(0.002)$ & $0.011(0.002)$ & $0.003(<0.001)$ & $0.05(0.10)$ & $0.70(0.11)$ & $0.25(0.02)$ & $1.1(0.2)$ & $1.2(0.1)$ \\
\hline & $\chi^{2}=2194.103$ & & & & $\chi^{2}=0.204$ & $\chi^{2}=36.271$ & & & \\
\hline & $P<0.001$ & & & & $P=0.651$ & $P<0.001$ & & & \\
\hline
\end{tabular}

This article is protected by copyright. All rights reserved

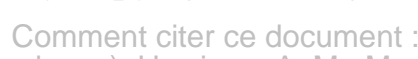

Gervais, L. (Auteur de correspondance), Hewison, A. M., Morellet, N., Bernard, M., Merlet, J.

Cargnelutti, B Chaval, Y Puiol, B. Quéméré, E. (Auteur de correspondance) (2020).

Pedigreefree quantitative genetic approach provides evidence for heritability of movement tactics in 


\section{Discussion}

There is a growing interest in how environmental heterogeneity and individual consistency can generate specialisation in movement tactics. However, an understanding of the causes of movement specialisation and its eco-evolutionary consequences is still lacking (Spiegel et al., 2017). Our study provides, as far as we know, the first evidence of substantial heritability and evolvability in space-use behaviour in the wild. It also illustrates the potential of genomic-based relatedness approaches to provide evidence for the evolutionary potential of formerly unexplored fitness-related traits in nonmodel species. In a wild large herbivore population inhabiting a spatially heterogeneous landscape, we found significant evidence of additive genetic variation for a suite of behavioural traits which are directly implicated in the management of the risk avoidance-resource acquisition trade-off and are related to fitness components (Bonnot et al., 2018; Monestier et al., 2015). Below we discuss the evolutionary implications of this in terms of how roe deer populations may adapt to global changes, such as landscape fragmentation, and highlight potential caveats in assessing the micro-evolutionary potential of space-use and movement behaviour in a heterogeneous landscape.

\section{Presence of personality variation in stress-management, space-use and movement behaviour}

Our results revealed the presence of substantial among-individual variation in all the studied behavioural and physiological traits. Average repeatability across traits (ca. $30 \%)$ was consistent with mean values observed by Bell (2009) and Holtmann (2017). However, repeatability differed markedly among behavioural traits. In particular, space-use behaviours were twice as consistent at the individual level as the other traits studied. This is not surprising, as roe deer are known to be sedentary and exhibit high spatial fidelity (Hewison, Vincent, \& Reby, 1998). Studies reporting the presence of consistent among-individual variation in space-use and movement behaviour are on the increase (Campos-Candela, Palmer, Balle, Álvarez, \& Alós, 2019; Hertel et al., 2019; Schirmer, Herde, Eccard, \& Dammhahn, 2019; Spiegel et al., 2017). While these findings have implications for our understanding of how individuals may respond to habitat fragmentation (Spiegel et al., 2017), little is currently known about the mechanisms underpinning individual-level consistency in space-use behaviour.

To facilitate comparisons of traits both within and across studies, it is important to estimate meanrather than variance- standardised among-individual variation for each trait (Dochtermann \& Royauté 2019). Indeed, repeatability estimates are, by definition, strongly dependent on the total phenotypic variance for a given trait which, in the specific case of space-use behaviours, is partly related to inherent differences in habitat structure. Consequently, although space-use behaviours were twice as repeatable compared to other non-spatial traits, mean-squared standardised among-

This article is protected by copyright. All rights reserved 
individual variation was much lower. This indicates that the higher repeatability of space-use behaviours is not due to more pronounced differences among individuals, but rather to a low level of within-individual variation. There is a clear lack of comparable estimates for mean-squared standardised among-individual variation in behavioural traits from other wild systems. More studies are necessary if we want to understand how and why the magnitude of among-individual differences varies across traits and populations (Dochtermann \& Royauté, 2019; Holtmann et al., 2017).

\section{Trait heritabilities, evolvabilities, and evolutionary implications}

Understanding the relationship between heritability and repeatability is of critical interest in behavioural ecology (Boake, 1989; Dochtermann et al., 2014). Indeed, adaptive explanations regarding the origin and maintenance of personality variation are widely assumed when using a phenotypic approach, but most often without investigating the mechanisms underpinning observed repeatability (genetic or environmental) (Dingemanse \& Wolf, 2010). Although it is now widely acknowledged that personality variation has, at least, some genetic basis (Dochtermann et al., 2014), there is still a lack of understanding of how the relative importance of genetic and non-genetic sources of variance might differ among personality traits (Réale et al., 2007). In a recent metaanalysis, Dochtermann et al. 2019 showed that heritability estimates varied from 14 to $45 \%$ among behavioural categories (e.g. activity, foraging, mating etc. behaviours). Similarly, we found that heritability estimates varied strongly among behavioural traits ranging from $21 \pm 8 \%$ for daily average speed to $70 \pm 11 \%$ for distance to roads. Comparing heritability among traits may lead to erroneous conclusions as it does not solely depend on the absolute magnitude of additive genetic variation. Houle (1992) therefore suggested using mean-standardize additive genetic variation that is a better measure of trait evolvability. Studies reporting heritability or evolvability of behaviour in wild populations are still scarce in comparison to other types of traits. Our results showed that behavioural traits exhibiting significant heritability also had non-zero evolvability. Therefore, consistent directional selection on those traits should lead to marked changes in the trait mean over a few hundred generations (1.1\%-4.6\% per generation per unit of selection). This is within the range of expected change reported for behavioural traits by Postma (2014) $(3.99 \pm 3.76 \%)$. However, the realization of this potential for evolutionary change is likely to be limited by constraining biological mechanisms (Pujol et al., 2018). For example, genetic correlations might act as constraints to evolution and it is now acknowledged that personality traits may form a syndrome based on genetic correlations that tie any change in one trait to the changes occurring in other traits (Blumstein, Lea, Olson, \& Martin, 2010; Careau et al., 2011; Petelle, Martin, \& Blumstein, 2015; Taylor et al., 2012). Thus, further studies will be required to understand whether this mechanism may affect the

This article is protected by copyright. All rights reserved 
evaluation of evolutionary potential in our study system. Moreover, selection pressures are expected to vary in space in this human-dominated landscape. For example, hunting intensity is variable across the landscape and may impose a selection pressure on behaviour (Leclerc, Zedrosser, \& Pelletier, 2017), with some personality types more prone to be killed than others (Ciuti et al., 2012; Lone, Loe, Meisingset, Stamnes, \& Mysterud, 2015). This may constrain the change in the trait mean distribution, as fluctuating selection might also influence the evolutionary response (Kruuk, Slate, \& Wilson, 2008; Pujol et al., 2018). To test this hypothesis, future work will investigate the predominant selection pressures and the responses of the roe deer in our study system.

\section{The limits of assessing microevolutionary potential in heterogeneous landscapes}

One of the novelties of our study is that we investigated the evolutionary potential of space-use and movement behaviour in a heterogeneous landscape. This is challenging because the observed heritability of a given trait may partly be due to environmental similarity when related individuals share close and/or similar habitats (Kruuk \& Hadfield, 2007; Thomson, Winney, Salles, \& Pujol, 2018). Such environmental similarity effects were observed in a wild red deer population (Cervus elaphus, Stopher et al., 2012), but were absent in Soay sheep (Ovis aries, Regan et al., 2017) and song sparrows (Melospiza melodia, Germain, Wolak, Arcese, Losdat, \& Reid, 2016). Whether this might affect the heritability estimates that we report for our study population remains to be explored, but cannot be ignored. Relatives are likely to share similar environments because the majority of juveniles are philopatric in our study population ( $60 \%$, Debeffe et al., 2012). Furthermore, although dispersers may travel relatively long distances (mean of $12.3 \pm 10.5 \mathrm{~km}$ Debeffe et al., 2012 in our study site) compared to the size of a home range (mean of $0.76 \mathrm{~km}^{2}$ Morellet et al., 2013), they may nevertheless select a settlement range which is as similar as possible to their natal range (Natal Habitat Preference Induction, Davis and Stamps, 2004). In the absence of additional information to account for maternal or space-sharing effects, caution must be taken when interpreting additive genetic variance for habitat-dependent traits because estimates might be thus inflated (see Andrews et al., 2018; Huisman, 2017; Thomson et al., 2018).

Accounting for environmental similarity between individuals implies that habitat use has no genetic basis and influences behaviour in an unidirectional way. However, causal relationships may be hard to disentangle under natural conditions if habitat use and behaviours share a confounded genetic and environmental basis. Home-range establishment during early life potentially covaries with personality-dependent spatial behaviour (Spiegel et al., 2017; Villegas-Ríos, Réale, Freitas, Moland, \& Olsen, 2018). Thus, different personality types might consistently differ in the environmental stimuli that they experience (Spiegel et al., 2017), which may generate among-individual variation in

This article is protected by copyright. All rights reserved 
behaviour (Bonnot et al., 2013, 2015; Coulon et al., 2008; Padié et al., 2015). This might be the case in roe deer because they use sub-seasonal home-ranges to track spatio-temporal variation in risk and resources (Couriot et al., 2018) and actively avoid exposure to human disturbance (e.g. roads, dwellings, agricultural crops) through adjustment of their circadian rhythm (Bonnot et al., 2013; Coulon et al., 2008; Martin et al., 2018; Padié et al., 2015). In addition, because roe deer are highly sedentary (Hewison, Vincent, \& Reby, 1998), habitat use during adulthood is strongly constrained by habitat selection during post-dispersal settlement. Hence, the habitat selection decision an individual takes at around one year of age (Debeffe et al., 2012) will have long-term consequences on the behavioural tactic it employs to trade-off risk avoidance and resource acquisition. Behavioural tactics employed during the juvenile stage may also influence habitat selection decisions during post-dispersal settlement and, more generally, behaviours during adulthood. In this situation, experimental approaches in semi-natural systems might be necessary to assess how personality variation is expressed when individuals are raised under identical or contrasting environmental conditions. This kind of approach might help clarify whether environmental drivers shape personality variation or personalities select particular environments.

\section{Genomic relatedness and spatial behaviour in wild non-model organisms: promises and caveats}

Genomic tools offer the opportunity for behavioural ecologists to study non-model organisms in natural populations (Bengston et al., 2018; Gienapp et al., 2017). GRM-based approaches have already been shown to have suitable power for estimating trait heritabilities in free ranging populations (Bérénos, Ellis, Pilkington, \& Pemberton, 2014; Perrier, Delahaie, \& Charmantier, 2018). Our study demonstrated that a GRM-based approach can be used with a relatively small sample size (e.g. a few hundred individuals). However, the critical points to consider appear to be variance in relatedness and the number of individual observations required to ensure enough statistical power to tease apart the genetic and non-genetic components of trait variation. Variance in relatedness in our data $\left(1.4 \times 10^{-3}\right)$ was within the range reported in Soay sheep $\left(1.3 \times 10^{-3}\right)$ (Bérénos et al., 2014) and blue tits $\left(4 \times 10^{-3}\right)$ (C. Perrier, pers. comm.), which is 100 times higher than the predicted values for unrelated humans (Vinkhuyzen et al., 2013, $2 \times 10^{-5}$ ).

The use of repeated measures is known to provide better accuracy when decomposing phenotypic variation (Martin, Nussey, Wilson \& Réale, 2011; Pol, 2012) and also helps to distinguish permanent environmental effects from residual effects (Wilson et al., 2010). Our results indirectly support the idea that the use of several observations per individual greatly improves statistical power to detect heritability (Åkesson, Bensch, Hasselquist, Tarka \& Hansson, 2008). Indeed, we were able to detect a

This article is protected by copyright. All rights reserved 
heritability of $0.21( \pm 0.08)$ using 205 individuals and 1856 observations for daily average speed, while we were unable to detect significant heritability for docility $(0.17 \pm 0.12)$ using 249 individuals and 334 observations, despite comparable levels of repeatability. Although this conclusion is not restricted to the GRM-approach, it is likely an important consideration for GRM-based heritability assessments based on small sample sizes that often lack adequate statistical power. Yet, to the best of our knowledge, no theoretical studies have investigated the statistical power of GRM-based approaches as a function of the number of individual observations, although similar issues have emerged in Genome Wide Association Studies (Rönnegård et al., 2016; Silva et al., 2017). Biologging techniques that provide multiple observations of a number of behaviours across time therefore appear as a powerful tool to overcome these limitations.

\section{Conclusion}

By combining intensive biologging technology and genome-wide data, we provided an empirical demonstration of substantial heritability and evolvability in movement and space-use tactics related to the management of the risk/resource trade-off. In a recent review, Tucker et al. (2018) showed that human activities have profound consequences on wild animal movements, but were unable to address the evolutionary consequences for their long-term sustainability. Our findings imply that wild populations have the potential to respond to selection pressure generated by human activity through micro-evolutionary change in spatial behaviours. The lack of comparable data from other wild systems highlights the need for more studies on the heritability and evolvability of stress management, space-use and movement behaviour under natural conditions. We conclude that the synergy between data-rich technologies that monitor the spatial locations of individuals and genome wide analysis paves the way for such advances.

\section{Data accessibility:}

Genomic Relatedness Matrix, spatial behaviour data and associated R-script are available from the Dryad Digital Repository: https:// doi:10.5061/dryad.dbrv15dxg

\section{ACKNOWLEDGMENTS:}

We are grateful to the many co-workers, students and volunteers who helped during field data collection, in particular Jean-Marc Angibault, Jean-Luc Rames, Bruno Lourtet, Denis Picot, Nicolas Cebe and Hélène Verheyden. We also thank Edinburgh genomics for RADseq data and the Genotoul Bioinfromatics Plateform Toulouse Midi-Pyrénées for providing help, computing and storage of RADseq data. We acknowledge John Hunt, Pim Edelaar and one anonymous reviewer for their comments that helped to improve the quality of this manuscript. We would also like to warmly

This article is protected by copyright. All rights reserved 
thank Ingrid David, Caroline Thomson and Isabel Winney for their advice on statistical analysis and Pierre de Villemereuil and Denis Réale for many helpful discussions on the project. This project was financially supported by the French National Institute for Agricultural Research (INRA), the UK Natural Environment Research Council (NERC), the Biomolecular Analysis Facility at the University of Edinburgh (NBAF901), the "PATCH" RPDOC ANR project (ANR-12-PDOC-0017-01) to Cécile Vanpé, and the "Mov-It" ANR project (ANR-16-CE02-0010-02) to Mark Hewison and Nicolas Morellet, the Centre National de la Recherche Scientifique (CNRS) core funding to Benoit Pujol, the EU within the framework of the Marie-Curie FP7 COFUND People Programme through the award of an Agreenskills fellowship to Erwan Quéméré, and the Federal University of Toulouse through the PhD scholarship of Laura Gervais (IDEX grant "GENEMOV" to Benoit Pujol and Erwan Quéméré).

\section{REFERENCES}

Abbas, F., Morellet, N., Hewison, A. J. M., Merlet, J., Cargnelutti, B., Lourtet, B., ... Verheyden, H. (2011). Landscape fragmentation generates spatial variation of diet composition and quality in a generalist herbivore. Oecologia, 167(2), 401-411. https://doi.org/10.1007/s00442-011-1994-0

Adrados, C., Verheyden-Tixier, H., Cargnelutti, B., Pépin, D., \& Janeau, G. (2003). GPS approach to study finescale site use by wild red deer during active and inactive behaviors. Wildlife Society Bulletin, 544-552.

Andrews, K. R., Adams, J. R., Cassirer, E. F., Plowright, R. K., Gardner, C., Dwire, M., ... Waits, L. P. (2018). A bioinformatic pipeline for identifying informative SNP panels for parentage assignment from RADseq data. Molecular Ecology Resources, 18(6), 1263-1281. https://doi.org/10.1111/1755-0998.12910

Åkesson M, Bensch S, Hasselquist D, Tarka M, Hansson B (2008) Estimating Heritabilities and Genetic Correlations: Comparing the 'Animal Model' with Parent-Offspring Regression Using Data from a Natural Population. PLOS ONE, 3(3): e1739. https://doi.org/10.1371/journal.pone.0001739

Archard, G. A., \& Braithwaite, V. A. (2010). The importance of wild populations in studies of animal temperament: Animal temperament in wild populations. Journal of Zoology, 281(3), 149-160. https://doi.org/10.1111/j.1469-7998.2010.00714.x

Bell, A. M., Hankison, S. J., \& Laskowski, K. L. (2009). The repeatability of behaviour: A meta-analysis. Animal Behaviour, 77(4), 771-783. https://doi.org/10.1016/j.anbehav.2008.12.022

Bengston, S. E., Dahan, R. A., Donaldson, Z., Phelps, S. M., van Oers, K., Sih, A., \& Bell, A. M. (2018). Genomic tools for behavioural ecologists to understand repeatable individual differences in behaviour. Nature Ecology \& Evolution, 2(6), 944-955. https://doi.org/10.1038/s41559-017-0411-4

Bérénos, C., Ellis, P. A., Pilkington, J. G., \& Pemberton, J. M. (2014). Estimating quantitative genetic parameters in wild populations: A comparison of pedigree and genomic approaches. Molecular Ecology, 23(14), 3434-3451. https://doi.org/10.1111/mec.12827

Blumstein, D. T., Lea, A. J., Olson, L. E., \& Martin, J. G. A. (2010). Heritability of anti-predatory traits: Vigilance and locomotor performance in marmots. Journal of Evolutionary Biology, 23(5), 879-887. https://doi.org/10.1111/j.1420-9101.2010.01967.x

This article is protected by copyright. All rights reserved 
Boake, C. R. B. (1989). Repeatability: Its role in evolutionary studies of mating behavior. Evolutionary Ecology, 3(2), 173-182. https://doi.org/10.1007/BF02270919

Bonnot, N., Bergvall, U. A., Jarnemo, A., \& Kjellander, P. (2018). Who's afraid of the big bad wolf? Variation in the stress response among personalities and populations in a large wild herbivore. Oecologia, 188(1), 85-95. https://doi.org/10.1007/s00442-018-4174-7

Bonnot, N., Goulard, M., Hewison, A. J. M., Cargnelutti, B., Lourtet, B., Chaval, Y., \& Morellet, N. (2018). Boldness-mediated habitat use tactics and reproductive success in a wild large herbivore. Animal Behaviour, 145, 107-115. https://doi.org/10.1016/j.anbehav.2018.09.013

Bonnot, N., Morellet, N., Verheyden, H., Cargnelutti, B., Lourtet, B., Klein, F., \& Hewison, A. J. M. (2013). Habitat use under predation risk: Hunting, roads and human dwellings influence the spatial behaviour of roe deer. European Journal of Wildlife Research, 59(2), 185-193. https://doi.org/10.1007/s10344012-0665-8

Bonnot, N., Verheyden, H., Blanchard, P., Cote, J., Debeffe, L., Cargnelutti, B., ... Morellet, N. (2015). Interindividual variability in habitat use: Evidence for a risk management syndrome in roe deer? Behavioral Ecology, 26(1), 105-114. https://doi.org/10.1093/beheco/aru169

Both, C., \& Visser, M. E. (2001). Adjustment to climate change is constrained by arrival date in a long-distance migrant bird. Nature, 411(6835), 296-298. https://doi.org/10.1038/35077063

Butler, D. G., Cullis, B. R., Gilmour, A. R., \& Gogel, B. J. (2009). ASReml-R reference manual (version 3). The State of Queensland, Department of Primary Industries and Fisheries: Brisbane, Qld.

Calenge, C. (2015). Analysis of animal movements in R: The adehabitatLT Package. 2015. R Package Version $n$ $0.3,20$.

Campos-Candela, A., Palmer, M., Balle, S., Álvarez, A., \& Alós, J. (2019). A mechanistic theory of personalitydependent movement behaviour based on dynamic energy budgets. Ecology Letters, 22(2), 213-232. https://doi.org/10.1111/ele.13187

Carbillet, J., Rey, B., Lavabre, T., Chaval, Y., Merlet, J., Débias, F., ... Gilot-Fromont, E. (2019). The neutrophil to lymphocyte ratio indexes individual variation in the behavioural stress response of wild roe deer across fluctuating environmental conditions. Behavioral Ecology and Sociobiology, 73(11), 144. https://doi.org/10.1007/s00265-019-2755-z

Careau, V., Thomas, D., Pelletier, F., Turki, L., Landry, F., Garant, D., \& Réale, D. (2011). Genetic correlation between resting metabolic rate and exploratory behaviour in deer mice (Peromyscus maniculatus). Journal of Evolutionary Biology, 24(10), 2153-2163. https://doi.org/10.1111/j.14209101.2011.02344.x

Catchen, J. M., Hohenlohe, P. A., Bassham, S., Amores, A., \& Cresko, W. A. (2013). Stacks: An analysis tool set for population genomics. Molecular Ecology, 22(11), 3124-3140. https://doi.org/10.1111/mec.12354

Charmantier, A., Buoro, M., Gimenez, O., \& Weimerskirch, H. (2011). Heritability of short-scale natal dispersal in a large-scale foraging bird, the wandering albatross. Journal of Evolutionary Biology, 24(7), 14871496. https://doi.org/10.1111/j.1420-9101.2011.02281.x

This article is protected by copyright. All rights reserved 
Ciuti, S., Muhly, T. B., Paton, D. G., McDevitt, A. D., Musiani, M., \& Boyce, M. S. (2012). Human selection of elk behavioural traits in a landscape of fear. Proceedings of the Royal Society of London B: Biological Sciences, rspb20121483. https://doi.org/10.1098/rspb.2012.1483

Coulon, A., Morellet, N., Goulard, M., Cargnelutti, B., Angibault, J.-M., \& Hewison, A. J. M. (2008). Inferring the effects of landscape structure on roe deer (Capreolus capreolus) movements using a step selection function. Landscape Ecology, 23(5), 603-614. https://doi.org/10.1007/s10980-008-9220-0

Couriot, O., Hewison, A. J. M., Saïd, S., Cagnacci, F., Chamaillé-Jammes, S., Linnell, J. D. C., ... Morellet, N. (2018). Truly sedentary? The multi-range tactic as a response to resource heterogeneity and unpredictability in a large herbivore. Oecologia, 187(1), 47-60. https://doi.org/10.1007/s00442-0184131-5

Davis, A. K., Maney, D. L., \& Maerz, J. C. (2008). The use of leukocyte profiles to measure stress in vertebrates: A review for ecologists. Functional Ecology, 22(5), 760-772. https://doi.org/10.1111/j.13652435.2008.01467.x

Davis, J. M., \& Stamps, J. A. (2004). The effect of natal experience on habitat preferences. Trends in Ecology \& Evolution, 19(8), 411-416. https://doi.org/10.1016/j.tree.2004.04.006

de Villemereuil, P. (2018). Quantitative genetic methods depending on the nature of the phenotypic trait. Annals of the New York Academy of Sciences, n/a-n/a. https://doi.org/10.1111/nyas.13571

de Villemereuil, P., Schielzeth, H., Nakagawa, S., \& Morrissey, M. (2016). General Methods for Evolutionary Quantitative Genetic Inference from Generalized Mixed Models. Genetics, 204(3), 1281-1294. https://doi.org/10.1534/genetics.115.186536

Debeffe, L., Lemaître, J. F., Bergvall, U. A., Hewison, A. J. M., Gaillard, J. M., Morellet, N., ... Kjellander, P. (2015). Short- and long-term repeatability of docility in the roe deer: Sex and age matter. Animal Behaviour, 109, 53-63. https://doi.org/10.1016/j.anbehav.2015.08.003

Debeffe, L., Morellet, N., Bonnot, N., Gaillard, J. M., Cargnelutti, B., Verheyden-Tixier, H., ... Hewison, A. J. M. (2014). The link between behavioural type and natal dispersal propensity reveals a dispersal syndrome in a large herbivore. Proceedings of the Royal Society B: Biological Sciences, 281(1790), 20140873-20140873. https://doi.org/10.1098/rspb.2014.0873

Debeffe, L., Morellet, N., Cargnelutti, B., Lourtet, B., Bon, R., Gaillard, J.-M., \& Mark Hewison, A. J. M. (2012). Condition-dependent natal dispersal in a large herbivore: Heavier animals show a greater propensity to disperse and travel further. Journal of Animal Ecology, 81(6), 1327-1327. https://doi.org/10.1111/j.1365-2656.2012.02014.x

Dempster, E. R., \& Lerner, I. M. (1950). Heritability of threshold characters. Genetics, 35(2), 212.

Dingemanse, N. J., \& Dochtermann, N. A. (2014). Individual behaviour: Behavioural ecology meets quantitative genetics. Quantitative Genetics in the Wild, 54-67.

Dingemanse, N. J., \& Wolf, M. (2010). Recent models for adaptive personality differences: A review. Philosophical Transactions of the Royal Society B: Biological Sciences, 365(1560), 3947-3958. https://doi.org/10.1098/rstb.2010.0221

This article is protected by copyright. All rights reserved 
Dochtermann, N. A., \& Royauté, R. (2019). The mean matters: Going beyond repeatability to interpret behavioural variation. Animal Behaviour, 153, 147-150.

https://doi.org/10.1016/j.anbehav.2019.05.012

Dochtermann, N. A., Schwab, T., \& Sih, A. (2014). The contribution of additive genetic variation to personality variation: Heritability of personality. Proceedings of the Royal Society B: Biological Sciences, 282(1798), 20142201-20142201. https://doi.org/10.1098/rspb.2014.2201

Edelaar, P., \& Bolnick, D. I. (2019). Appreciating the Multiple Processes Increasing Individual or Population Fitness. Trends in Ecology \& Evolution, 34(5), 435-446. https://doi.org/10.1016/j.tree.2019.02.001

Elston, R. C., Hill, W. G., \& Smith, C. (1977). Query: Estimating" Heritability" of a dichotomous trait. Biometrics, 33(1), 231-236.

Garcia-Gonzalez, F., Simmons, L. W., Tomkins, J. L., Kotiaho, J. S., \& Evans, J. P. (2012). Comparing Evolvabilities: Common Errors Surrounding the Calculation and Use of Coefficients of Additive Genetic Variation. Evolution, 66(8), 2341-2349. https://doi.org/10.1111/j.1558-5646.2011.01565.x

Germain, R. R., Wolak, M. E., Arcese, P., Losdat, S., \& Reid, J. M. (2016). Direct and indirect genetic and finescale location effects on breeding date in song sparrows. Journal of Animal Ecology, 85(6), 16131624. https://doi.org/10.1111/1365-2656.12575

Gervais, L., Perrier, C., Bernard, M., Merlet, J., Pemberton, J., Pujol, B., \& Quéméré, E. (2019). RAD-sequencing for estimating GRM-based heritability in the wild: A case study in roe deer. Molecular Ecology Resources, 19(5), 1205-1217. https://doi.org/10.1111/1755-0998.13031

Gienapp, P., Fior, S., Guillaume, F., Lasky, J. R., Sork, V. L., \& Csilléry, K. (2017). Genomic Quantitative Genetics to Study Evolution in the Wild. Trends in Ecology \& Evolution, 32(12), 897-908. https://doi.org/10.1016/j.tree.2017.09.004

Gilmour, A. (2010). Handling Non Positive Definite relationship matrices in Mixed Models. Proceedings of the World Congress on Genetics Applied to Livestock Production, Methods and tools: Software and bioinformatics-Poster Sessions, 0957.

Gilmour, A. R. (2019). Average information residual maximum likelihood in practice. Journal of Animal Breeding and Genetics, 136(4), 262-272. https://doi.org/10.1111/jbg.12398

Grafen, A. (1984). Natural Selection, Kin Selection and Group Selection. Retrieved March 19, 2019, from http://users.ox.ac.uk/ grafen/cv/KandD2ed.pdf

Greenwood, P. J., Harvey, P. H., \& Perrins, C. M. (1979). The Role of Dispersal in the Great Tit (Parus major): The Causes, Consequences and Heritability of Natal Dispersal. Journal of Animal Ecology, 48(1), 123142. https://doi.org/10.2307/4105

Hansen, T. F., Pélabon, C., \& Houle, D. (2011). Heritability is not Evolvability. Evolutionary Biology, 38(3), 258. https://doi.org/10.1007/s11692-011-9127-6

Hertel, A. G., Leclerc, M., Warren, D., Pelletier, F., Zedrosser, A., \& Mueller, T. (2019). Don't poke the bear: Using tracking data to quantify behavioural syndromes in elusive wildlife. Animal Behaviour, 147, 91104. https://doi.org/10.1016/j.anbehav.2018.11.008

This article is protected by copyright. All rights reserved 
Hewison, A. J. M., Morellet, N., Verheyden, H., Daufresne, T., Angibault, J.-M., Cargnelutti, B., ... Cebe, N. (2009). Landscape fragmentation influences winter body mass of roe deer. Ecography, 32(6), 10621070. https://doi.org/10.1111/j.1600-0587.2009.05888.x

Hewison, A. J. M., Vincent, J. P., \& Reby, D. (1998). Social organisation of European roe deer. The European Roe Deer: The Biology of Success. Scandinavian University Press, Oslo, 189-219.

Holtmann, B., Lagisz, M., \& Nakagawa, S. (2017). Metabolic rates, and not hormone levels, are a likely mediator of between-individual differences in behaviour: A meta-analysis. Functional Ecology, 31(3), 685-696. https://doi.org/10.1111/1365-2435.12779

Houle, D. (1992). Comparing evolvability and variability of quantitative traits. Genetics, 130(1), 195-204.

Huisman, J. (2017). Pedigree reconstruction from SNP data: Parentage assignment, sibship clustering and beyond. Molecular Ecology Resources. https://doi.org/10.1111/1755-0998.12665

Kruuk, L. E. B., \& Hadfield, J. D. (2007). How to separate genetic and environmental causes of similarity between relatives: Separating genetic and environmental effects. Journal of Evolutionary Biology, 20(5), 1890-1903. https://doi.org/10.1111/j.1420-9101.2007.01377.x

Leclerc, M., Zedrosser, A., \& Pelletier, F. (2017). Harvesting as a potential selective pressure on behavioural traits. Journal of Applied Ecology, 54(6), 1941-1945.

Kruuk, L. E.B, Slate, J., \& Wilson, A. J. (2008). New answers for old questions: the evolutionary quantitative genetics of wild animal populations. Annual Review of Ecology, Evolution, and Systematics, 39, 525548.

Lone, K., Loe, L. E., Meisingset, E. L., Stamnes, I., \& Mysterud, A. (2015). An adaptive behavioural response to hunting: Surviving male red deer shift habitat at the onset of the hunting season. Animal Behaviour, $102,127-138$.

Lynch, M., \& Walsh, B. (1998). Genetics and analysis of quantitative traits (Vol. 1). Sinauer Sunderland, MA.

Magurran A. E., May R. M., \& Wilson David Sloan. (1998). Adaptive individual differences within single populations. Philosophical Transactions of the Royal Society of London. Series B: Biological Sciences, 353(1366), 199-205. https://doi.org/10.1098/rstb.1998.0202

Martin, J. G.A, \& Réale, D. (2008). Temperament, risk assessment and habituation to novelty in eastern chipmunks, Tamias striatus. Animal Behaviour, 75(1), 309-318.

Martin, J. G. A., Nussey, D. H., Wilson, A. J., \& Réale, D. (2011). Measuring individual differences in reaction norms in field and experimental studies: a power analysis of random regression models: Power analysis of random regression models. Methods in Ecology and Evolution, 2(4), 362-374. https://doi.org/10.1111/j.2041-210X.2010.00084.x

Martin, J., Vourc'h, G., Bonnot, N., Cargnelutti, B., Chaval, Y., Lourtet, B., ... Morellet, N. (2018). Temporal shifts in landscape connectivity for an ecosystem engineer, the roe deer, across a multiple-use landscape. Landscape Ecology, 33(6), 937-954. https://doi.org/10.1007/s10980-018-0641-0

Meyer, K. (2019). "Bending” and beyond: Better estimates of quantitative genetic parameters? Journal of Animal Breeding and Genetics, 136(4), 243-251. https://doi.org/10.1111/jbg.12386

This article is protected by copyright. All rights reserved 
Moberg, G. P., \& Mench, J. A. (2000). The biology of animal stress: Basic principles and implications for animal welfare. CABI.

Moe, R. O., \& Bakken, M. (1997). Effects of Handling and Physical Restraint on Rectal Temperature, Cortisol, Glucose and Leucocyte. Acta Vet. Scand, 38(1), 29-39.

Monestier, C., Morellet, N., Gaillard, J.-M., Cargnelutti, B., Vanpé, C., \& Hewison, A. J. M. (2015). Is a proactive mum a good mum? A mother's coping style influences early fawn survival in roe deer. Behavioral Ecology, 26(5), 1395-1403. https://doi.org/10.1093/beheco/arv087

Montané, J., Marco, I., Lopez-Olvera, J. R., Rossi, L., Manteca, X., \& Lavin, S. (2007). Effect of acepromazine on the signs of capture stress in captive and free-ranging roe deer (Capreolus capreolus). Veterinary Record, 160(21), 730-738.

Morellet, N., Bonenfant, C., Börger, L., Ossi, F., Cagnacci, F., Heurich, M., ... Mysterud, A. (2013). Seasonality, weather and climate affect home range size in roe deer across a wide latitudinal gradient within Europe. Journal of Animal Ecology, 82(6), 1326-1339. https://doi.org/10.1111/1365-2656.12105

Morellet, N., Verheyden, H., Angibault, J.-M., Cargnelutti, B., Lourtet, B., \& Hewison, M. A. J. (2009). The Effect of Capture on Ranging Behaviour and Activity of the European Roe Deer Capreolus capreolus. Wildlife Biology, 15(3), 278-287. https://doi.org/10.2981/08-084

Mousseau, T. A., \& Roff, D. A. (1987). Natural selection and the heritability of fitness components. Heredity, 59(2), 181-197. https://doi.org/10.1038/hdy.1987.113

Nakagawa, S., \& Schielzeth, H. (2010). Repeatability for Gaussian and non-Gaussian data: A practical guide for biologists. Biological Reviews, 85(4), 935-956. https://doi.org/10.1111/j.1469-185X.2010.00141.x

Nilson, J., Brönmark, C., Hansson, L.-A., \& Chapman, B. (2014). Individuality in movement: The role of animal personality. https://doi.org/DOI: 10.1093/acprof:oso/9780199677184.003.0006

Padié, S., Morellet, N., Hewison, N., Martin, J.-L., Bonnot, N., Cargnelutti, B., \& Chamaillé-Jammes, S. (2015). Roe deer at risk: Teasing apart habitat selection and landscape constraints in risk exposure at multiple scales. Oikos, 124(11), 1536-1546. https://doi.org/10.1111/oik.02115

Parmesan, C. (2006). Ecological and Evolutionary Responses to Recent Climate Change. Annual Review of Ecology, Evolution, and Systematics, 37(1), 637-669. https://doi.org/10.1146/annurev.ecolsys.37.091305.110100

Perrier, C., Delahaie, B., \& Charmantier, A. (2018). Heritability estimates from genome wide relatedness matrices in wild populations: Application to a passerine, using a small sample size. Molecular Ecology Resources, O(0). https://doi.org/10.1111/1755-0998.12886

Petelle, M. B., Martin, J. G. A., \& Blumstein, D. T. (2015). Heritability and genetic correlations of personality traits in a wild population of yellow-bellied marmots (Marmota flaviventris). Journal of Evolutionary Biology, 28(10), 1840-1848. https://doi.org/10.1111/jeb.12700

Peterson, B. K., Weber, J. N., Kay, E. H., Fisher, H. S., \& Hoekstra, H. E. (2012). Double Digest RADseq: An Inexpensive Method for De Novo SNP Discovery and Genotyping in Model and Non-Model Species. PLOS ONE, 7(5), e37135. https://doi.org/10.1371/journal.pone.0037135

Pinheiro, J., \& Bates, D. (2006). Mixed-effects models in S and S-PLUS. Springer Science \& Business Media.

This article is protected by copyright. All rights reserved 
Pol, M. V. D. (2011). Quantifying individual variation in reaction norms: how study design affects the accuracy, precision and power of random regression models. Methods in Ecology and Evolution, 3(2), 268-280. https://doi.org/10.1111/j.2041-210x.2011.00160.x

Postma, E. (2014). Four decades of estimating heritabilities in wild vertebrate populations: Improved methods, more data, better estimates. Quantitative Genetics in the Wild, 16, 33.

Pujol, B., Blanchet, S., Charmantier, A., Danchin, E., Facon, B., Marrot, P., ... Winney, I. (2018). The Missing Response to Selection in the Wild. Trends in Ecology \& Evolution, 33(5), 337-346. https://doi.org/10.1016/j.tree.2018.02.007

Ratcliffe, P. R., \& Mayle, B. A. (1992). Age determination of roe deer. Forestry Commission Bulletin, 105, $26-28$. Réale, D., Reader, S. M., Sol, D., McDougall, P. T., \& Dingemanse, N. J. (2007). Integrating animal temperament within ecology and evolution. Biological Reviews, 82(2), 291-318. https://doi.org/10.1111/j.1469185X.2007.00010.x

Regan, C. E., Pilkington, J. G., Berenos, C., Pemberton, J. M., Smiseth, P. T., \& Wilson, A. J. (2017). Accounting for female space sharing in St. Kilda Soay sheep (Ovis aries) results in little change in heritability estimates. Journal of Evolutionary Biology, 30(1), 96-111.

Roff, D. A., Stirling, G., \& Fairbairn, D. J. (1997). The evolution of threshold traits: A quantitative genetic analysis of the physiological and life-history correlates of wing dimorphism in the sand cricket. Evolution, 51(6), 1910-1919.

Rönnegård, L., McFarlane, S. E., Husby, A., Kawakami, T., Ellegren, H., \& Qvarnström, A. (2016). Increasing the power of genome wide association studies in natural populations using repeated measures evaluation and implementation. Methods in Ecology and Evolution, 7(7), 792-799. https://doi.org/10.1111/2041-210X.12535

Saastamoinen, M., Bocedi, G., Cote, J., Legrand, D., Guillaume, F., Wheat, C. W., ... Delgado, M. del M. (2018). Genetics of dispersal. Biological Reviews, 93(1), 574-599. https://doi.org/10.1111/brv.12356

Schirmer, A., Herde, A., Eccard, J. A., \& Dammhahn, M. (2019). Individuals in space: Personality-dependent space use, movement and microhabitat use facilitate individual spatial niche specialization. Oecologia, 189(3), 647-660. https://doi.org/10.1007/s00442-019-04365-5

Silva, C. N. S., McFarlane, S. E., Hagen, I. J., Rönnegård, L., Billing, A. M., Kvalnes, T., ... Husby, A. (2017). Insights into the genetic architecture of morphological traits in two passerine bird species. Heredity, 119(3), 197-205. https://doi.org/10.1038/hdy.2017.29

Spiegel, O., Leu, S. T., Bull, C. M., \& Sih, A. (2017). What's your move? Movement as a link between personality and spatial dynamics in animal populations. Ecology Letters, 20(1), 3-18. https://doi.org/10.1111/ele.12708

Spiegel O., Leu Stephan T., Sih Andrew, Godfrey Stephanie S., \& Bull C. Michael. (2015). When the going gets tough: Behavioural type-dependent space use in the sleepy lizard changes as the season dries. Proceedings of the Royal Society B: Biological Sciences, 282(1819), 20151768. https://doi.org/10.1098/rspb.2015.1768

This article is protected by copyright. All rights reserved 
Stanton-Geddes, J., Yoder, J. B., Briskine, R., Young, N. D., \& Tiffin, P. (2013). Estimating heritability using genomic data. Methods in Ecology and Evolution, 4(12), 1151-1158. https://doi.org/10.1111/2041210X.12129

Stirling, D. G., Réale, D., \& Roff, D. A. (2002). Selection, structure and the heritability of behaviour. Journal of Evolutionary Biology, 15(2), 277-289. https://doi.org/10.1046/j.1420-9101.2002.00389.x

Stopher, K. V., Walling, C. A., Morris, A., Guinness, F. E., Clutton-Brock, T. H., Pemberton, J. M., \& Nussey, D. H. (2012). Shared Spatial Effects on Quantitative Genetic Parameters: Accounting for Spatial Autocorrelation and Home Range Overlap Reduces Estimates of Heritability in Wild Red Deer. Evolution, 66(8), 2411-2426. https://doi.org/10.1111/j.1558-5646.2012.01620.x

Taylor, R. W., Boon, A. K., Dantzer, B., Réale, D., Humphries, M. M., Boutin, S., ... McAdam, A. G. (2012). Low heritabilities, but genetic and maternal correlations between red squirrel behaviours. Journal of Evolutionary Biology, 25(4), 614-624. https://doi.org/10.1111/j.1420-9101.2012.02456.x

Thomson, C. E., Winney, I. S., Salles, O. C., \& Pujol, B. (2018). A guide to using a multiple-matrix animal model to disentangle genetic and nongenetic causes of phenotypic variance. PLOS ONE, 13(10), e0197720. https://doi.org/10.1371/journal.pone.0197720

Tucker, M. A., Böhning-Gaese, K., Fagan, W. F., Fryxell, J. M., Van Moorter, B., Alberts, S. C., ... Avgar, T. (2018). Moving in the Anthropocene: Global reductions in terrestrial mammalian movements. Science, 359(6374), 466-469.

Tuomainen, U., \& Candolin, U. (2011). Behavioural responses to human-induced environmental change. Biological Reviews, 86(3), 640-657. https://doi.org/10.1111/j.1469-185X.2010.00164.x

Van Oers, K., \& Sinn, D. (2013). Quantitative and molecular genetics. Animal Personalities: Behavior, Physiology, and Evolution, 149-200.

Van Vleck, L. D. (1972). Estimation of heritability of threshold characters. Journal of Dairy Science, 55(2), 218225.

Villegas-Ríos, D., Réale, D., Freitas, C., Moland, E., \& Olsen, E. M. (2017). Individual level consistency and correlations of fish spatial behaviour assessed from aquatic animal telemetry. Animal Behaviour, 124, 83-94. https://doi.org/10.1016/j.anbehav.2016.12.002

Villegas-Ríos, D., Réale, D., Freitas, C., Moland, E., \& Olsen, E. M. (2018). Personalities influence spatial responses to environmental fluctuations in wild fish. Journal of Animal Ecology, O(0). https://doi.org/10.1111/1365-2656.12872

Vinkhuyzen, A. A., Wray, N. R., Yang, J., Goddard, M. E., \& Visscher, P. M. (2013). Estimation and partition of heritability in human populations using whole-genome analysis methods. Annual Review of Genetics, 47, 75-95.

Ward-Fear, G., Brown, G. P., Pearson, D. J., West, A., Rollins, L. A., \& Shine, R. (2018). The ecological and life history correlates of boldness in free-ranging lizards. Ecosphere, 9(3), e02125. https://doi.org/10.1002/ecs2.2125

Waser, P. M., \& Jones, W. T. (1989). Heritability of dispersal in banner-tailed kangaroo rats, Dipodomys spectabilis. Animal Behaviour, 37, 987-991.

This article is protected by copyright. All rights reserved 
Wilson, A. J. (2008). Why h2 does not always equal VA/VP?: Why h2 does not always equal VA/VP? Journal of Evolutionary Biology, 21(3), 647-650. https://doi.org/10.1111/j.1420-9101.2008.01500.x

Wilson, A. J., Réale, D., Clements, M. N., Morrissey, M. M., Postma, E., Walling, C. A., ... Nussey, D. H. (2010). An ecologist's guide to the animal model. Journal of Animal Ecology, 79(1), 13-26. https://doi.org/10.1111/j.1365-2656.2009.01639.x

Wong, B. B. M., \& Candolin, U. (2015). Behavioral responses to changing environments. Behavioral Ecology, 26(3), 665-673. https://doi.org/10.1093/beheco/aru183

Yang, J., Lee, S. H., Goddard, M. E., \& Visscher, P. M. (2011). GCTA: A Tool for Genome-wide Complex Trait Analysis. American Journal of Human Genetics, 88(1), 76-82. https://doi.org/10.1016/j.ajhg.2010.11.011

\section{Figures:}

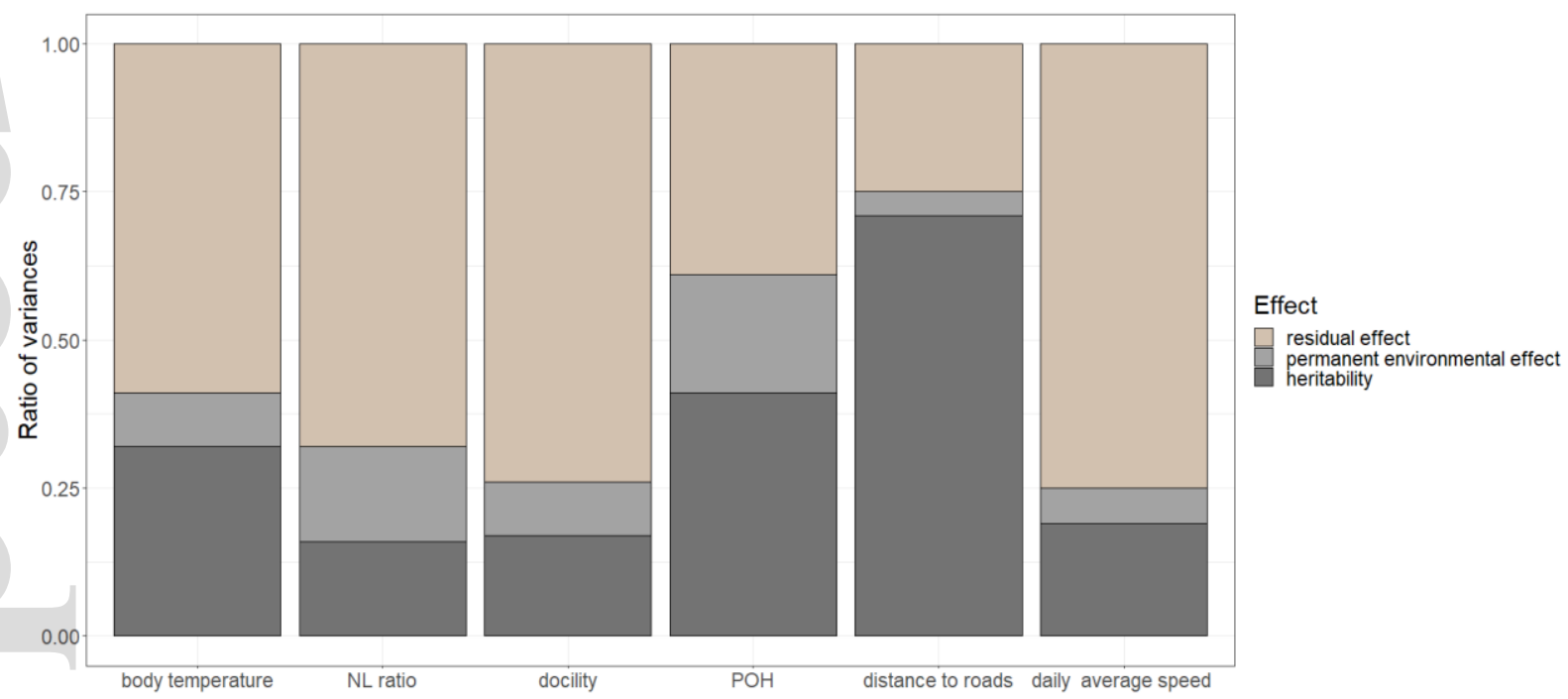

Figure 1: Variance partitioning of the stress management, space-use and movement behaviours

Proportion of the phenotypic variance of traits explained by heritability, permanent environmental effects and residual effects (within-individual variance + measurement error). Repeatability corresponds to the sum of permanent environmental effects (light grey) and heritability (dark grey).

This article is protected by copyright. All rights reserved 